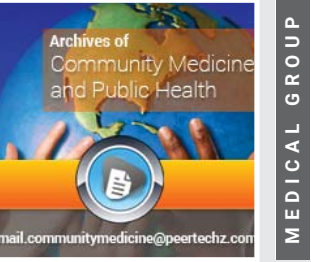

\title{
Health Care Reform in China - A Rural Rehabilitation Service Station
}

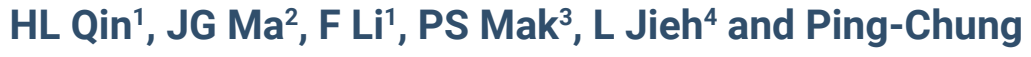 \\ Leung $^{5 *}$ \\ ${ }^{1}$ Manager, Qin Huai Social Work Service Centre, Xian (NGO, Xian), China \\ ${ }^{2}$ Orthopeadic Surgeon, FuPing County Hospital, China \\ ${ }^{3}$ Professor Emeritus, Dept of Social Worker, The Hong Kong Polytechnic University, Hong Kong, Hong \\ Kong \\ ${ }^{4}$ TCM Doctor, FuPing County Hospital, China
}

${ }^{5}$ Professor Emeritus, Department of Orthopaedics, The Chinese University of Hong Kong, Hong Kong

Received: 07 July, 2020

Accepted: 01 August, 2020

Published: 03 August, 2020

*Corresponding author: Ping-Chung Leung, Professor Emeritus, Department of Orthopaedics, The Chinese University of Hong Kong, Hong Kong, 5/F School of Public Health Building, Prince of Wales Hospital, Shatin, Hong Kong, Tel: (852) 2252 8868; Fax: (852) 2632 5441; E-mail: pingcleung@cuhk.edu.hk https://www.peertechz.com

\section{Check for updates}

\section{Abstract \\ A Rural Rehabilitation Service Station - an experimental model catered for elderlies and mildly disabled people is being established in a village near Xian, Shanxi Province. A non-government charity organization registered in Xian is responsible for the establishment. It has organized a team of Rural Medical Workers, Therapists, Traditional Chinese Medicine Doctors and Social Workers responsible for the development. The Service Station is receiving users regularly, and on special occasions workshops are organized. Professional support is regularly offered by one county hospital and a Charity Organization in Hong Kong. \\ Towards the end of 2019, a proper review on the Service Station was be carried out by academics and professionals. It is expected that this unique establishment would provide valuable information for similar attempts to provide Rehabilitation Service in the rural areas of China.}

\section{Introduction}

Since the turn of the last century, one of the widely heard civil outcry throughout China has been "Getting medical care is not only difficult but too expensive". Reforming in the Medical and Health Care System has been top on the national agenda.

In 2008, the Minster of Medical and Health Services Dr. Chen $\mathrm{Zu}$ put forward a detailed plan to reform the Medical Services. The plan included 5 major categories: -
i. Establish more venues for Public Health Services
ii. Expansion of the Medical Insurance Coverages
iii. Build a Network of Primary Health Care Services
iv. Improve the Drug Provision System and

v. Ensure Public Hospitals are serving people on welfare direction.

The plan aims at a speedy outcome, expecting that in 5 to 10 years' time the difference between cities and rural areas should be narrowed. It was hoped that, reaching 2020, city dwellers and rural people alike could enjoy middle to high quality health care [1].

Ten years passed, the results of the Reform are gradually revealed.

Public Health infrastructures have been extensively built throughout the country since the SARS epidemic, demonstrating clearly the vast investment on disease prevention and infection control. Medical Insurance Schemes in the rural and city areas are being merged while the Government support for the Premium has increased many folds. However, the remaining 
three other areas of reform would need more time. Primary Health care service has never started in the past and the Hospitals of different levels remain the major venues giving varieties of special clinical care, not of primary health nature. Problems in Public Hospital Services and Drug Costs are still awaiting better solutions.

\section{Rehabilitation service in china}

During the same period of Reform in Medical and Health Services, rehabilitation in the clinical context has been included in different levels of clinical services, mainly in the hospitals and, in the major cities, scanty rehabilitation centers. The need for clinical rehabilitation is expectedly huge, judging from the physical training services required after surgical treatment, and the large volume of aging and disabled people. Since the insurance coverage and rehabilitation subsidy extend to hospitals and other venues, the heavy utilization of rather limited facilities has been a universal phenomenon and overloading is the rule [2].

The over-loading has been the result of influx of rural patients to small county hospitals and small city dwellers to city hospitals. While sophisticated rehabilitation training requires special arrangement with hospital bases, training for the maintenance of physical ability and prevention of health hazards could be organized outside the hospitals. Establishing rural rehabilitation service stations in suitable village settings, distant from hospitals could be the answer.

\section{An experimental model - Bei-Ling rural rehabilitation service station}

The Xian Qin Huai Social Work Service Centre $(\mathrm{XQH})$ is a Non-Government Charity Organization registered in Xian, Shanxi in 2016, giving rehabilitation related Social Service to people in Xian and Fu-Ping County nearby. It is managed by a small group of local Social Workers who are supported by a Charity Organization in Hong Kong, called "Operation Concern" (OC). OC has been supporting a county hospital in FuPing County for over 20 years on rehabilitation related services and development. The group of workers have full knowledge of the Fu-Ping County, its need for rehabilitation services and facilities available. After several months of discussions and consultations a Prototype designated to A Rural Rehabilitation Service Station is proposed and subsequently put to practice.

\section{Bei-Ling rural rehabilitation service station (BLRS)}

Bei-Ling is a village within Fu-Ping County. The village administration appreciates XQH's initiative of establishing the Service Station with which village people need not go to the County Hospital for physical training. The County Rehabilitation Association is also giving warm support.

Since its establishment in March 2017, the Station consists of a single storey complex of 300 sq meters, facing an open space of 1500 sq meters. Basic equipments for physical training are available inside the complex (Figures 1-3). The environmental set up is carefully completed and selection of rehabilitation facilities are acquired with full considerations of

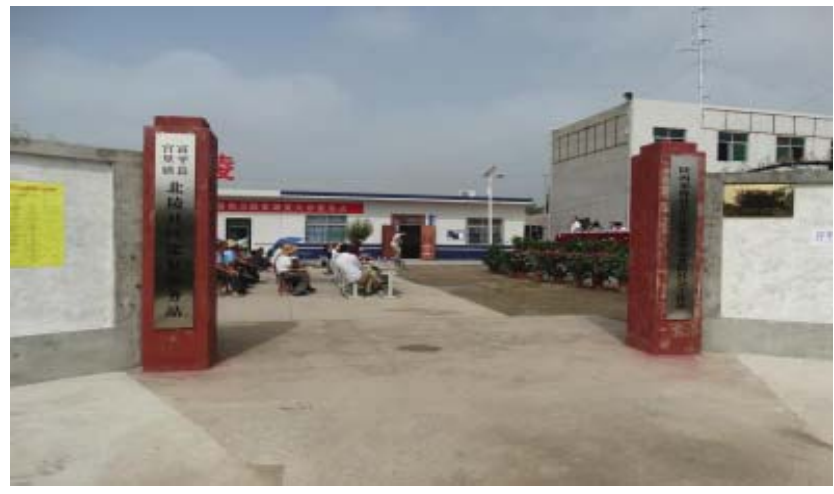

Figure 1: Entry to the Rehabilitation Service Station.

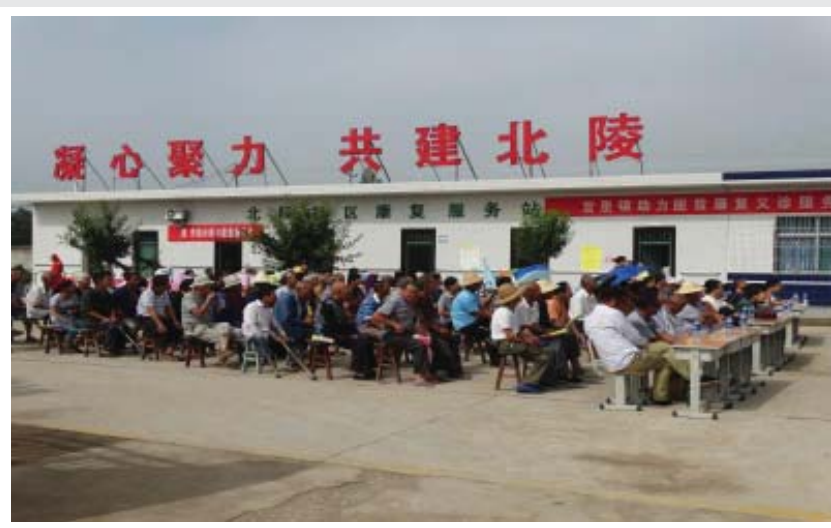

Figure 2: Courtyard outside Station.

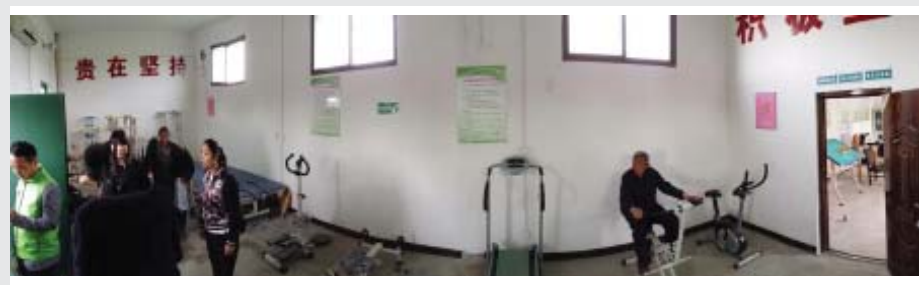

Figure 3: Inside of Service Station with simple equipments.

safety. Rural people in the vicinity are welcome to pay regular visits and use the facilities in the day time. Registered visitors will get instructions from local qualified Orthopaedic Surgeons / Rehab Workers / Traditional Chinese Medicine doctors when they come for special guidance. The instructors come from one County Hospital twice a week.

Apart from the provision of a rehabilitation station for the rural people, particularly the elderlies, regular training and servicing activities need to be provided. They include the following: -

\begin{tabular}{|c|c|}
\hline Regular Activities & Provider \\
\hline $\begin{array}{c}\text { Short Instruction Sessions on } \\
\text { Musculoskeletal Problems }\end{array}$ & Orthopaedists Rehab Trainers \\
\hline Survey, Home visits & $\begin{array}{c}\text { Social Workers } \\
\text { Rehab Trainers }\end{array}$ \\
\hline Counselling (Social \& Psychological) & Social Workers \\
\hline $\begin{array}{c}\text { Professional Enhancement Workshops } \\
\text { (Quarterly) }\end{array}$ & Experts from Hong Kong \\
\hline
\end{tabular}




\section{A review after two Years' service}

Rural need for rehabilitation: BLRS has received a free venue from the Village Administration. The venue is originally planned for the recreational need of the elderly people. Converting this venue to provide Rehabilitation Services has expanded the original idea of simple recreation to the provision of multiple needs of the rural people. The original idea of providing them with sitting and chatting spaces for various social activities is fine; adding health promotion related elements would suit them better.

At the planning stage, the social worker team has completed a household survey of Bei-Ling with particular reference to those who would make use of the BLRS. It was found that four groups of people will be particularly fond of the station. They are:

I. Those who have suffered from stroke with varying degrees of disability;

II. Chronic diseases requiring rehabilitation;

III. Common musculoskeletal problems and

IV. Elderlies who are starting to have obvious cognitive and physical deteriorations.

It seems obvious that the rural need for Rehabilitation facilities is not confined to the usual hospital orientated musculoskeletal training, but the large number of elderly people require care for chronic diseases, cognitive deteriorations and related preventive measures.

Table 1, Gives the monthly data related to clients served, their problems and functional response in 2017-2018.

Table 1: Monthly data of clients served, their rehabilitation problems and general functional outcome.

\begin{tabular}{|c|c|c|c|c|}
\hline $\begin{array}{c}\text { Clients with } \\
\text { Special Rehab } \\
\text { needs }\end{array}$ & Number & $\begin{array}{c}\text { Training with } \\
\text { Supervision }\end{array}$ & $\begin{array}{c}\text { Self- } \\
\text { maintained } \\
\text { training }\end{array}$ & $\begin{array}{c}\text { General } \\
\text { Function } \\
\text { Outcome }\end{array}$ \\
\hline $\begin{array}{c}\text { Post stroke } \\
\text { hemiparesis }\end{array}$ & 20 & $1 / 2$ day / week & regular & $\begin{array}{c}\text { Functional } \\
\text { improvement }\end{array}$ \\
$\begin{array}{c}\text { Long term } \\
\text { skeletal } \\
\text { disabilities }\end{array}$ & 25 & $1 / 2$ day / week & regular & $\begin{array}{c}\text { Better } \\
\text { maintained }\end{array}$ \\
\hline $\begin{array}{c}\text { Chronic skeletal } \\
\text { pain }\end{array}$ & $80-90$ & On need & regular & $\begin{array}{c}\text { Objective } \\
\text { relieves }\end{array}$ \\
\hline $\begin{array}{c}\text { Elderlies with } \\
\text { exercise needs }\end{array}$ & Over 100 & On request & On need & $\begin{array}{c}\text { Good } \\
\text { appreciation }\end{array}$ \\
\hline
\end{tabular}

\section{Rehabilitation equipments}

A Service centre would need the provision of basic equipments for the physical training of fundamental musculoskeletal activities: which include purely manual strengthening tools and some powered machines. In the village setting, particular attention needs to be taken on safety and durability. Over-sophistication should not be preferred since supervision and training would be minimal.
Now that elderly people are expected to be the major users, facilities focusing on Fall Prevention and simple cognitive training would need to be provided. For the latter, simple computer-aided screens with appropriate programs might serve the purpose.

\section{The Serving Team}

Medical members: Although the focus of attention is not on acute or specific medical problems, medical members need to take a leading role to ensure safety, to provide appropriate intervention on need and to fulfill clients' expectations. Rural areas in China have the unique situation that most of the medical doctors and therapists are Traditional Chinese Medicine (TCM) type of graduates. They should be welcome to give service in the Rural Station. Their expertise on manual procedures like massage and acupuncture are highly appreciated.

Regular visits of the medical members carry the role of instructions and education. Twice weekly arrangements have been able to maintain the enthusiasm of visitors and users.

Therapists: Rural therapists are usually TCM doctors or special nurses. They are fully respected and trustworthy therapists in the rural setting. TCM therapists freely give their expert advice and manual training if required.

The common challenge for both doctors and therapists is to start adapting to the rural need which is not only related to musculoskeletal problems, but even more importantly, related to the prevention of those problems and cognitive deteriorations in the elderlies.

Social workers: In the first place, Social Work in China is understood as a new stream of profession and the number of qualified experts are limited, particularly in hospital related settings. However, in this pioneer establishment of a Rural Rehabilitation Service Station, support from social workers is essential. They need to organize household visits and surveys to understand the general socio-economic situation, the health needs and problems, as well as the rural administration. The social workers also serve as the bridge between the rural people and the medical members. They try to understand the family, home environments related, and psychological problems of the rural clients and help them to get the best benefits from the Service Station Table 2.

When workshops, educational activities and recreational social gatherings are being organized, they are also the organizing front-liners.

With this unique Servicing Team, the BLRS manages to maintain continual self-evaluating procedures in the establishment of this Model Service Station.

Training workshops: A rural rehabilitation service is required to provide basic training facilities, to provide advice and education to the clients. During its establishment, professional support from experts is necessary. In order to maintain its continual function, and to ensure professional improvement the local service providers need to be trained. 
Since its establishment the BLRS has regularly held workshops for the training of both professional medical workers, social workers, local workers, volunteers and patients. Each workshop is dedicated towards a practical common problem Table 3.

The workshops start with brief background knowledge, followed by video demonstrations, then life demonstrations. Instructors include academics from Hong Kong; local orthopaedic surgeons and therapists. TCM doctors would give their views and introduce traditional ways of therapy.

The workshops are very well received. The all-party participations allow a genuine exchange of ideas among the members of the Service Team and provide eye-opening exposures for non-medicals like volunteers, rural visitors and patients.

Table 2: Services given by one full-time and two part-time social workers.

\begin{tabular}{|c|c|}
\hline Work nature & Frequency \\
\hline Weekly visit with Rehab Expert & Every week \\
\hline Weekly visit to receive consultation & Every week \\
\hline Home visits & On demand 3-4 x /month \\
\hline $\begin{array}{c}\text { Special events (meet volunteers / } \\
\text { workshop / training) }\end{array}$ & $3-4 \times /$ month \\
\hline
\end{tabular}

Table 3: Shows Workshops held since 2017
Workshop

$1 \checkmark$ Common chronic musculoskeletal problems

$\checkmark$ Hemiplegia

$\checkmark$ Low Back pain

- Neck pain

$\checkmark$ Upper Limb problems

$\checkmark$ Fall Prevention

Lower Limb problems

$\checkmark$ Dementia - Cognitive Decline

\section{Discussion}

Rehabilitation Service is recognized internationally as an important though under-looked Health Service [3]. As the number of elderly people rapidly rises, rehabilitation carries an extra-load within elderly services. Since China started its Health Care reform, hospital care in the cities have been receiving extra resources in all areas, including rehabilitation. Further extension of rehabilitation facilities to the rural areas is a logical development. The $\mathrm{XQH}$ is attempting to build a rural model, not only for the chronic diseased and disabled, but mainly for the elderlies on rehabilitation maintenance and prevention of age-related hazards. This model depends on the collaboration between three parties: orthopedists, rehabilitation workers and social workers. It is not only a service provision station, but also an experimental model to identify the problems, to provide more knowledge and to facilitate further planning. It is also a model of collaboration between the county hospital, the rural administration, local non-governmental organization and outside China Charity Organization [4].
Contributions from Social Workers appear crucial and important. They function as a bridging agent between the professionals and rural people. They bring forward the medicosocial issues existing in the users' families; they communicate and liaise well with the village administrations; and they give suggestions on the further pursue of rehabilitation solutions. Unfortunately, the Social work profession is just developing in China and it is difficult to invite social workers to work in rural areas.

The working team of BLRS has the wonderful privilege of owing three social-work members. It appears that in other situations, without social workers' expert planning, starting similar rural services could be difficult. Nevertheless, volunteers from the same rural area and outside, like nearby county districts, could be trained to handle simple medicosocial problems related to the elderlies and disabled. Our volunteers in Bei-Ling did gain much our appreciation with their enthusiastic support.

On completion of two years, a comprehensive review was conducted by a divergent group of experts, which included Administrators of different collaborators, Rehabilitation leaders, members of the four working teams, TCM experts, academics from China and Hong Kong and also the rural users and elderlies. Problems already identified: like difficulties in the transportation of flail users and a better format of health education, was discussed and proposals made.

On completion of the review an Instructional Manual basing on the workshops and overall experiences was produced as a practical record and working manual. The two year's experience and contents of training workshops are properly edited for further use (Figure 4). Without doubt, the BLRS

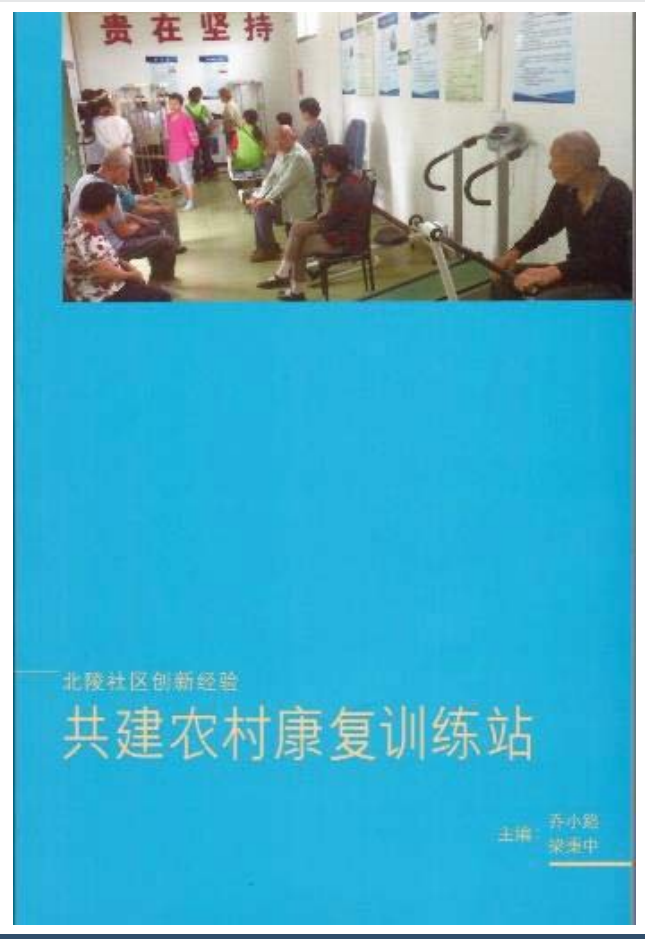

Figure 4: Instructional Manual for the Rural Rehabilitation Service Station 
model will be able to offer practical references to other rural areas preparing to set up low-cost infrastructures for the wellbeing of elderlies and chronic-patients [5,6]. Since the need for rural rehabilitation in China is so vast, to carry on with further establishment would not only require the continual support of the local government, but the involvement of local and may be international charity organizations would be of crucial importance.

\section{Conclusion}

we have worked hard to establish the pioneer project of rehabilitation service in the rural area and have given an honest report. Our experience could be useful but is obviously limited. We are determined to carry on with the efforts and look forward to collaboration, advice, comments and encouragements from rehabilitation expert and colleagues.

\section{Conflict of interest}

The Rural Rehabilitation Service Station has been a charity project unrelated to any commercial funding body.

\section{Acknowledgement}

The Operation Concern Charitable, Hong Kong, a registered non-governmental charity organization has been responsible for funding involved in the establishment of the Rural Rehabilitation Service Station.

\section{References}

1. Chen Z (2009) Launch of the health care reform plain in China. Lancet 273: 1322-1324. Link: https://bit.ly/30gP8UH

2. Disabled Peoples Association, Shanxi (in Chinese) (2012) Standardizing Infrastructure of Disabled People's Training Centres. Disabled Peoples Ass, Shanxi 122.

3. WHO (2010) Announcement on Need of Rehabilitation. WHO announcement.

4. China Ministry of Health (in Chinese) (2016) Guidelines for Establishing Medical Sanatorium. Civil Service Dept documents.

5. People's Congress Announcement (in Chinese) (2018) Putting Elderly People's Medical and Health Care to the Top Priority. China People's Congress.

6. People's Congress Announcement (in Chinese) (2018) Putting Elderly People's Medical and Health Care to the Top Priority. China People's Congress.
Discover a bigger Impact and Visibility of your article publication with

\section{Peertechz Publications}

\section{Highlights}

* Signatory publisher of ORCID

* Signatory Publisher of DORA (San Francisco Declaration on Research Assessment)

* Articles archived in worlds' renowned service providers such as Portico, CNKI, AGRIS, TDNet, Base (Bielefeld University Library), CrossRef, Scilit, J-Gate etc.

* Journals indexed in ICMJE, SHERPA/ROMEO, Google Scholar etc.

* OAI-PMH (Open Archives Initiative Protocol for Metadata Harvesting)

* Dedicated Editorial Board for every journal

* Accurate and rapid peer-review process

- Increased citations of published articles through promotions

* Reduced timeline for article publication

Submit your articles and experience a new surge in publication services (https://www.peertechz.com/submission).

Peertechz journals wishes everlasting success in your every endeavours.

Copyright: @ 2020 Qin HL, et al. This is an open-access article distributed under the terms of the Creative Commons Attribution License, which permits unrestricted use distribution, and reproduction in any medium, provided the original author and source are credited. 